\title{
Pós-modernidade e Turismo: Reflexões Acerca da Experiência Turística no Contexto das Agências de Viagens.
}

\author{
Ana Luiza de Albuquerque Tito ${ }^{a}$ \\ Paula Normandia Moreira Brumattib \\ Wilker Ricardo de Mendonça Nóbregac
}

\begin{abstract}
Resumo
O fenômeno turístico constitui um projeto de sociedade que se apropria de espaços e os transforma segundo normas e valores que lhe são próprios. As motivações de viagens e os destinos turísticos fazem parte de uma rede de significados pessoais e sociais e sua análise auxilia compreender a nova convivência social e as novas possibilidades mercadológicas. Estudos acerca do comportamento do consumidor no turismo trata a motivação como determinante básico do consumo e o processo de tomada de decisão como algo individual. Assim, pretende-se refletir o turista pós-moderno, suas necessidades e busca contínua por experiências de vida estabelecendo relação com as estratégias mercadológicas para a oferta das viagens no contexto das agências de viagens. Para tanto, foram entrevistadas seis agências de viagens do município de Natal- RN. Os resultados da pesquisa sinalizam que, segundo as agências de viagem, o consumidor do turismo tem buscado experiências, embora apontam que elas ainda não desenvolvem ações estratégicas neste sentido. Pensar o turismo contemporâneo não é descartar os elementos de natureza econômica e mercadológica que o constitui, mas compreender que sua essência está nas viagens como prática humana e a subjetividade que ela implica. Palavras-chave: Pós-turista; Experiência; Agências de viagem.
\end{abstract}

\section{Abstract \\ Postmodernity and Tourism: Reflections on the Tourist Experience in the Context of Travel Agencies.}

The tourism phenomenon constitutes a project of society that appropriates spaces and transforms them according to norms and values that are their own. The motivations of travel and tourist destinations are part of a network of personal and social meanings and their analysis helps to understand the new social coexistence and the new market possibilities. Studies on consumer behavior in tourism treats motivation as the basic determinant of consumption and the decision-making process as something individual. Therefore, it intend to reflect the postmodern tourist, his needs and continuous search for life experiences establishing relationship with the marketing strategies for the travel offer in the context of travel agencies. For this purpose, six travel agencies from Natal-RN were interviewed. The results of the research indicate that, according to travel agencies,

a. Mestranda do Programa de Pós-graduação em Turismo PPGTUR da Universidade Federal do Rio Grande do Norte (UFRN). Natal, Rio Grande do Norte, Brasil. E-mail: analuiza.tito@hotmail.com

b. Doutoranda do Programa de Pós-graduação em Turismo- PPGTUR (UFRN). Natal, Rio Grande do Norte, Brasil. E-mail: paulanmb@yahoo.com.br

c. Doutor em Ciências Sócio Ambientais na Universidade do Pará (UFPA). Docente da Universidade Federal do Rio Grande do Norte (UFRN). Natal, Rio Grande do Norte, Brasil. E-mail: wilkernobrega@ yahoo.com.br 
the tourism consumer has sought experiences, although they point out that they have not yet developed strategic actions in this direction. To think contemporary tourism is not to discard the economic and market elements that constitute it, but to understand that its essence is in travel as human practice and the subjectivity that it implies.

Keywords: Post-tourist; Experience; Travel agencies.

\section{Resumen}

\section{La Postmodernidad y Turismo: Reflexiones sobre la Experiencia Turística en el Contexto de las Agencias de Viajes.}

El fenómeno turístico es un proyecto social que se apropia de los espacios y los transforma de acuerdo con las normas y valores propios. Las motivaciones de viaje y los destinos son parte de una red de significados personales y sociales y su análisis ayuda a entender las nuevas relaciones sociales y nuevas posibilidades de comercialización. Los estudios sobre el comportamiento del consumidor en el turismo consideran la motivación como un determinante básico de consumo y el proceso de toma de decisiones como algo individual. De este modo, se pretende reflejar el turista post-moderno, sus necesidades y la búsqueda permanente de experiencias de vida que establecen relación con las estrategias de marketing para la prestación de los viajes en el contexto de las agencias de viajes. Para ello, se entrevistó a seis agencias de viajes en la ciudad de Natal-RN. Los resultados del estudio indican que, de acuerdo con las agencias de viajes, el consumidor de turismo ha buscado experiencias, aunque señalan que no han desarrollado acciones estratégicas en este sentido. Pensar el turismo contemporáneo no es descartar la naturaleza económica y los elementos de mercado que lo constituye, sino que su esencia está en el viaje como la práctica humana y la subjetividad que ella conlleva.

Palabras clave: Post-turismo; La experiencia; Agencias de viajes.

\section{INTRODUÇÃo}

O homem desloca-se no território desde o início dos tempos, quando os primitivos percorriam grandes distâncias em busca de comida e abrigo necessários à sobrevivência. Ao longo da história, as motivações das viagens passam a satisfazer outras necessidades humanas como comerciais, educacionais, religiosas, econômicas, de saúde e lazer.

A partir da segunda metade do século XX, diversos fatores contribuíram para o desenvolvimento e expansão das viagens. Mudanças econômicas e políticas no cenário internacional; a evolução das relações sociais com o trabalho e direitos adquiridos, como as férias garantidas e remuneradas; os avanços tecnológicos na comunicação e nos transportes, possibilitaram viagens mais cômodas e rápidas e o barateamento dos custos de promoção e dos serviços turísticos; ampliando as oportunidades para o lazer e para o turismo.

Então, hoje, o fenômeno turístico é considerado como um projeto de sociedade que se apropria de espaços e os transforma segundo normas e valores que lhe são próprios e que transcendem os limites espaciais. Para Maffesoli (2001, p.51), o nomadismo pós-moderno com origem no politeísmo de valores é "uma espécie de 'pulsão migratória' incitando [o indivíduo] a mudar de lugar, de hábito, de parceiros, e isso para realizar a diversidade de facetas de sua personalidade". Em 
suma, representado pelo desejo do novo lugar, por uma vida de encantamento e reencantamento do mundo.

Assim, as motivações de viagens e os espaços turísticos, alguns entendidos como destinos, fazem parte de uma rede de significados pessoais e sociais, e sua análise nos auxilia a compreender não só uma nova convivência social e sua relação com a natureza, mas também, novas possibilidades mercadológicas que envolvem todo o processo de desenvolvimento e de consolidação da atividade turística e muitos de seus atores sociais.

0 indivíduo em sua viagem, enquanto turista, faz uso de bens e serviços que em seu conjunto define a demanda turística, que, por sua vez, é influenciada por modelos de comportamento do consumidor, o turista (Cooper, 2007). Nesse sentido, a compreensão de seu comportamento, motivações e de suas necessidades que levam à decisão de compra do produto turístico representam o determinante básico do consumo e o processo de tomada de decisão como algo individual.

Com o advento da globalização, estratégias globais para identificar, desenvolver e comercializar diferentes produtos e serviços turísticos se fortalecem, principalmente através das redes corporativas de empresas agregadas à cadeia produtiva do turismo (Beni, 2003). Assim, as inovações mercadológicas e as diferentes formas de comunicação relacionadas ao mundo contemporâneo, são capazes de criar condições e oportunidades aos consumidores que pareciam impossíveis, indesejáveis ou não faziam parte de seu conhecimento.

Neste contexto, o presente artigo pretende refletir acerca do turista pós-moderno, suas necessidades e busca contínua por experiências de vida estabelecendo relação com as estratégias mercadológicas para a oferta das viagens e como isto vem sendo trabalhado ou sentido pelas agências de viagens do município de Natal, estado do Rio Grande do Norte.

Para tanto, este estudo está embasado numa pesquisa bibliográfica e descritiva referente a evolução histórica e teórica do turismo, apresentando o turista pós-moderno baseado no conceito de Molina e fundamentado pela ideia de errância e nomadismo de Maffesoli, que buscam sinalizar possibilidades de uma compreensão mais holística e fenomenológica contemporânea da vida humana em seu contexto social.

Também foi realizada uma pesquisa exploratória acerca da atual visão empresarial sobre as necessidades deste turista pós moderno e as novas possibilidades das agências de viagens influenciadas neste contexto do comportamento do consumidor e no consumo das viagens. Para tanto, foram entrevistadas (06) seis agências de viagens e turismo do município de Natal- RN, com perguntas referentes às mudanças sentidas em relação ao perfil do turista, aos destinos turísticos procurados, tempo de permanência das viagens e às práticas de atividades nos destinos.

\section{Evolução HISTÓrica do TURISMO: UMA BREVE INTRODUÇÃO}

Compreender o turismo requer reflexões sobre as viagens. Os primórdios da existência humana são caracterizados por sociedades nômades, as quais se deslocavam essencialmente por razões de sobrevivência, atreladas à busca por 
alimentos e abrigos. Na medida em que as sociedades adquirem condições para produção do seu alimento, começam a se fixar e, assim, as viagens passam a acontecer em detrimento de outros fatores.

Figueiredo (2010) elucida por meio de relatos de viagens esta trajetória de motivações relacionadas às conjunturas históricas, políticas, econômicas, sociais e culturais de cada época. Porém, o mesmo autor considera que:

"O conceito de viagem ultrapassa o simples deslocamento espacial, para um deslocamento entre o mesmo e o diferente. 0 estudo do turismo seria então o estudo de uma forma particular de viagem, da viagem que pressupõe o lazer, da experiência do retorno, e da viagem-pacote: a mercadoria turismo" (Figueiredo, 2010, p.285).

Nesse sentido, muitos autores (Figueiredo, 2010; De La Torre, 1994; Molina 2003; Boyer, 2003) atribuem fases distintas que compõem a evolução histórica das viagens e da consolidação do turismo, considerando que o mesmo só surge efetivamente a partir de meados do século XIX.

Oscar de La Torre (1994) elenca três fases relativas ao desenvolvimento do turismo. A primeira, que ocorre até meados do século XIX, o qual denomina de "turismo incipiente elitista" reservado a uma minoria burguesa. A segunda, a qual denomina de fase de "transição", caracterizada pelo início da popularização da atividade, que se estende até meados do século XX. E por fim, a terceira, a partir da Segunda Guerra Mundial, na qual surge o turismo de massa permanente até os dias atuais.

Molina (2003) também estabelece três estágios de desenvolvimento do fenômeno. Para o autor, o estágio "Pré-Turismo", que se encerra com a prática do Grand Tour - como um rito de passagem educacional dos jovens da elite britânica - e a recuperação dos balneários como destinos importantes de intensa vida social. 0 segundo estágio, o "Turismo Industrial”, subdividido em três categorias: primitivo, originado no século XIX até o início da Segunda Guerra Mundial; industrial maduro que se estende até meados da década de 1980; e, finalmente, a terceira categoria, o Pós-Industrial, que passa a apresentar mudanças significativas da prática turística mundial decorrente das mudanças tecnológicas, comunicacionais e mercadológicas. E o terceiro estágio representado pelo "Pós-Turismo" como um novo paradigma teórico-metodológico, ainda em processo de desenvolvimento, análise e enriquecimento conceitual, onde o sujeito turístico se torna mais autônomo em detrimento das tecnologias de alta eficiência e do uso intensivo da informação como recurso estratégico das empresas.

Cisne e Gastal (2010) também discutem a periodização histórica do turismo na visão de alguns autores, e, em resumo, elencam três fases principais relevantes em sua evolução histórica. A fase pré-turismo ou antecessora que compreende as viagens orientadas por inúmeros motivos políticos, religiosos, desbravadores e não necessariamente comerciais, até o Grand Tour da Idade Moderna, fase então, em que os indivíduos que se deslocam representam os viajantes. A segunda fase, relacionada ao início das viagens programadas, com seu precursor Thomas Cook, facilitadas pelo desenvolvimento dos transportes decorrente da Revolução Industrial e a invenção da máquina a vapor, seguido por um período de guerras e instabilidade econômica, quando ocorre a interrupção do crescimento da atividade. E a terceira fase, quando a prática turística é retomada após a Segunda 
Guerra Mundial deixando de ser exclusivamente elitista passando a ocorrer em grande escala, consolidando o turismo de massa e, simultaneamente, os estereótipos pejorativos dos indivíduos viajantes, agora os turistas de fato. Surge então, o que Figueiredo (2014) denomina, a "viagem-pacote: a mercadoria turismo".

Com as mudanças das concepções de vida a viagem torna-se uma faceta da vida social, o que leva, ao mesmo tempo, o crescimento "dos meios de viagem", a oferta dos serviços e produtos relacionados ao turismo (Boyer, 2003).

A figura 01 apresenta a compilação das ideias sobre a periodização do turismo sugerida pelos autores supracitados, destacando a classificação dos indivíduos viajantes de acordo com os períodos identificados.

Figura 1: Periodização do turismo segundo de La Torre (1994), Molina (2003) e Cisne e Gastal (2010).

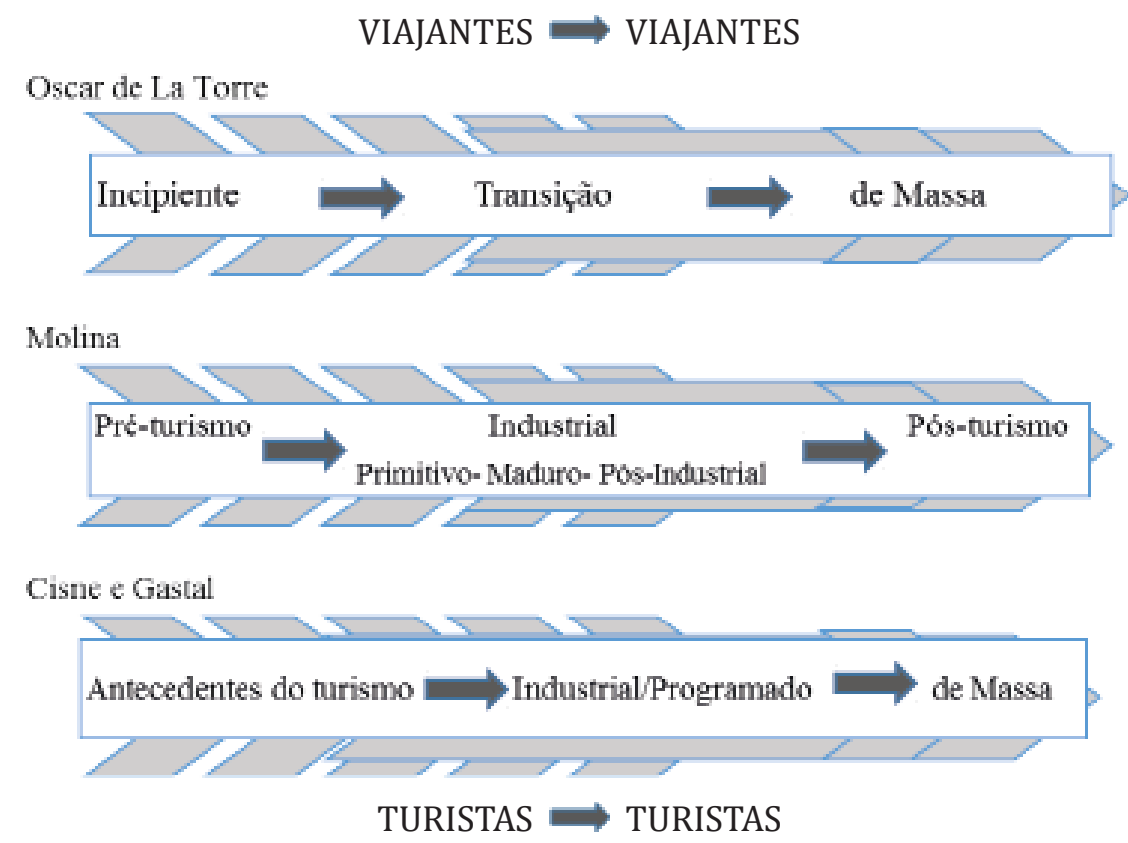

Fonte: Elaborada pelos próprios autores.

\section{VIAJANTES OU TURISTAS: REFLEXÕES SOBRE O TURISTA PÓS- MODERNO}

Compreender o nascimento do turismo a partir do século XIX é considerar que a atividade não trata apenas de indivíduos que se deslocam para um destino por qualquer motivo pessoal ou societal, mas sim trata de uma prática humana que envolve o deslocamento, a intenção do retorno, a prática do lazer e, não menos relevante, a utilização de equipamentos, serviços e produtos facilitadores deste deslocamento e da experiência da viagem.

"O turismo é um tipo de consumo diferente dos outros, pois se realiza em outro local e não visa à satisfação de uma necessidade fundamental do homem [...] o turismo é um produto da evolução sociocultural e pode ser definido assim: Turismo = conjunto dos fenômenos resultantes da viagem e da estadia temporária de pessoas 
fora de seu domicílio, na medida em que este deslocamento satisfaz, no lazer, uma necessidade cultural da civilização industrial" (Boyer, 2003, p. 16).

Entender o turismo como fenômeno da modernidade é atribuir significados distintos entre viajantes e turistas. Na modernidade, com o processo de industrialização, é evidente que a práxis do turismo estava relacionada a fuga das atividades cotidianas, do estresse urbano e dos problemas pessoais atrelados as condições de trabalho e, de alguma maneira, viajar consistia numa forma de assegurar o tempo livre. Segundo Krippendorf (2001), a viagem é apresentada como um subterfúgio para se escapar da escravidão do cotidiano e encontrar a tão almejada 'liberdade' e, desse modo, o turismo se transforma na indústria da diversão, do prazer e de status social (Meyer, 2007), onde o destino das viagens constitui um outro polo o anticotidiano. Os interesses dos indivíduos eram passíveis a manipulação de mercado, pois o essencial era a evasão do espaço cotidiano e suas obrigações, sem abrir mão das comodidades.

Neste contexto, Figueiredo e Ruschmann (2004) afirmam que "o turismo é uma forma de viagem exclusiva da modernidade e pilar da pós-modernidade". Para os autores, o viajante é aquele indivíduo que viaja por motivos nobres e subjetivos em busca de sua identidade e diversidades, provoca inquietações por onde passa.

"A busca da identidade compreende um movimento de partida, viagem (percurso) e chegada, seja o retorno ao ponto de origem, seja a chegada a um novo lugar. No primeiro movimento, viajar significa desprender-se, despojar-se do ruim, do insuportável da vida, estar em suspensão. 0 percurso, estado de viagem, simboliza um rito de passagem, em que o provisório está presente e o mundo, o cotidiano, fica em suspensão. 0 intervalo é o espaço e o tempo. 0 lugar não existe como espaço" (Figueiredo; Ruschmann, 2004, p. 173).

Nesta discussão, a aventura consiste no elemento básico tanto para o viajante quanto ao turista e a curiosidade representa um elemento variável. Porém, os autores concluem que "as críticas ao turismo e ao turista são fruto de uma leitura preconceituosa das viagens de turismo de massa, empreendidas por trabalhadores da classe média mundial" (Figueiredo; Ruschmann, 2004, p.183). Na perspectiva do turismo consumido em grandes escalas é possível esta interpretação onde a experiência turística encerra em si própria.

Considerando a complexidade cultural e social da pós-modernidade e o processo de globalização mundial novas concepções e valores sobre as experiências de viagens são possíveis. Maffesoli (2001) ressalta que a retomada da errância, independentemente da viagem, passa a representar uma necessidade de experiência individual e de valor social. A errância envolve a mobilidade, que por sua vez, relaciona-se ao desejo de aventura da existência por meio de experiências culturais, científicas, sexuais, religiosas, vividas em tempo real e coletivamente através das redes de comunicação ou das viagens e turismo.

Para o turista do século XXI a viagem não representa mais somente um status social, mas uma forma de complementação da experiência da vida diária e de suprir o espírito aventureiro e curioso do ser humano. A difusão do capitalismo de livre mercado, a abertura das fronteiras, a privatização, a desregulamentação 
da economia e as tecnologias integradoras colaboraram para as novas relações entre tempo, espaço e sujeito. As férias deixam de acontecer apenas em um momento do ano pré-estabelecido, para serem fragmentadas ao longo dos meses. 0 consumo na pós-modernidade não se baseia tão somente na produção em massa, com produtos pré-determinados, mas abre-se para as particularidades individuais e o individualismo passa a representar uma realidade fortalecida nos pilares da sociedade contemporânea. 0 turista passa então a exigir produtos diferenciados, personalizados, flexíveis e qualificados que vão ao encontro de seu encantamento e reencantamento com o mundo.

No próprio campo dos estudos do turismo é possível observar uma evolução nestes estudos. Panosso Netto (2005), aponta que os estudos turísticos partem de abordagens técnicas e positivistas da atividade, com teóricos como Luiz Fernandéz Fuster, Walter Hunziker, K. Krapf, S. Medlik e A. J. Burkart; perpassam pela fase paradigmática, com a apresentação do modelo sistêmico aplicado ao turismo por seus estudiosos Neil Leiper, Mário Carlos Beni, Alberto Sessa e Roberto Boullón; até o período das "novas abordagens", em que teóricos como, Jafar Jafari e John Tribe tentam recolocar o ser humano como principal elemento do fenômeno turístico. Neste sentido, a compreensão de uma maior complexidade do fenômeno é evidenciada e estas novas abordagens passam a investigar de modo multi ou interdisciplinar, as viagens e o turismo, numa perspectiva do ser, o turista, e suas influências sociais e psicológicas.

Uriely (2005) ressalta que o turismo na pós- modernidade é cada vez mais presente no cotidiano das pessoas e que os estudos não devem desconsiderar os sujeitos em suas análises, uma vez que a viagem e o consumo relacionado a ela representam uma escolha pessoal e, portanto, subjetiva. Turistas que viajam de modo similar não necessariamente compartilham a mesma experiência e, portanto, o turismo passa a ser fenômeno plural e diverso. A autenticidade da experiência turística está relacionada a uma perspectiva construtivista, onde o turista atribui significado aos objetos que estão dispostos e, portanto, a segmentação dos produtos turísticos ou a tipologia dos turistas não devem excluir o sujeito da análise. Para Sheller e Urry (2004, p.1), o turismo também envolve relações de memórias e performances "corpos com gênero e raça, emoções e atmosferas".

O entendimento da razão do processo dinâmico das relações entre grupos que ocasionam as mudanças pode ser encontrado na busca de satisfação de necessidades e desejos. Os atores sociais são seres humanos submetidos a diversos campos de controle de suas ações, porém, impulsionados por fatores de natureza subjetiva, como sentimentos e emoções. Esses aspectos psicológicos, somados às características biológicas, provocam atitudes, iniciativas, decisões e realizações (Tomazzoni; Dorion; Zottis, 2008, p. 139).

A reconfiguração do turismo também é influenciada pela nova concepção de desenvolvimento, o desenvolvimento sustentável, apoiado numa interpretação interdisciplinar e na noção de "espaço" material e imaterial, lugar concreto e abstrato, cenário de interações, conflitos e transformações, ponto de contato simbólico entre local e global, e que influencia todos os seus atores sociais. (Irving et.al., 2005). 0 pós-turista valoriza a cultura, tem a consciência que as paisagens naturais devem ser preservadas e movimentam-se em busca de ícones que re- 
presentem a identidade local e a memória coletiva contidas nos bens culturais materiais e imateriais.

Nesse contexto é possível dizer que o turista contemporâneo reassume, em parte, o papel de viajante, uma vez que vivenciar a experiência turística torna-se parte do seu desenvolvimento pessoal e não somente por uma necessidade do anticotidiano e contrária ao trabalho. As motivações de viagens são múltiplas e circunstanciais. Este turista mantém o papel de consumidor, porém a subjetividade da viagem não poderá ser negligenciada, uma vez que a curiosidade humana permanece e o espírito da errância faz parte do cotidiano.

Pezzi e Vianna (2015, p.170) apresentam uma reflexão acerca do significado antropológico de experiência e apontam que pode ser relacionada à atividade turística de duas maneiras: a primeira, através do Turismo de Experiência que "é o termo mercadologicamente utilizado para descrever uma forma de formatar produtos turísticos, inserindo o turista como protagonista de sua própria viagem" e, a segunda, a experiência turística, que "em sua concepção antropológica, visa a olhar o indivíduo na interrupção de seu comportamento rotinizado e repetitivo". Para eles, a experiência no turismo deve causar algum estranhamento que faça com que o indivíduo se reconecte ao passado e ressignifique suas lembranças, reintegrando as experiências vividas na viagem em seu cotidiano.

Como afirma Beni (2003), na contemporaneidade, as empresas dominantes serão aquelas que focarem no planejamento e na organização das experiências, aquelas que conseguirem conquistar as mentes e emoções dos clientes. A vantagem competitiva destas empresas será a sua capacidade de conhecer as expectativas dos clientes e agregar valores em seus produtos e serviços, algo que ultrapasse única e exclusivamente o campo da visão, mas atinja os quatro sentidos e o coração, ou seja, sejam capazes de proporcionar um acontecimento memorável (Pezzi e Vianna, 2015).

\section{RECONFIGURAÇÕES DO MERCADO CONSUMIDOR DAS AGÊNCIAS DE VIAGENS}

No atual cenário de mudanças em função das tecnologias da informação, crises econômicas e do nível de conhecimento dos consumidores, torna-se necessário aprofundar a análise sobre o comportamento do consumidor. Hoje, os indivíduos estão cada vez mais seletivos na escolha dos serviços e produtos, buscando aqueles que proporcionem experiências capazes de gerar uma maior satisfação no campo pessoal e profissional.

A evolução da sociedade perpassa pelas sociedades agrícola, industrial, informacional e por último a sociedade dos sonhos, onde nesta última etapa, é aberto espaço também para o lado emocional e imaterial da humanidade. Neste contexto, acredita-se que as pessoas passarão a ser vistas muito menos pelos bens possuídos e cada vez mais pela confiança em suas histórias e pelos sentimentos demonstrados (Panosso Netto e Gaeta, 2010).

No campo do turismo, com o advento da internet novas mudanças se deram no comportamento do consumidor relacionado ao despertar para a realização de uma viagem, passando pela forma de se adquirir informações e produtos turísticos e finalizando na questão motivacional. Porém, a análise das motivações é 
complexa e apresenta inúmeras variantes no processo. Num mundo dinâmico, a motivação de hoje nem sempre é a mesma de amanhã e um único grupo de indivíduos pode apresentar diversas motivações pessoais.

Kaynok et. al. (1996 como citado em Swarbrooke e Horner, 2002), num estudo sobre viajantes irlandeses encontraram diferenças significativas entre turistas de diferentes idades, sexos, nível cultural, renda e estado civil. Os jovens preferiam férias que lhes favorecessem a prática de atividades, enquanto os mais velhos buscavam destinações para descansar, com oportunidades de visitar lugares interessantes. Os entrevistados do nível cultural mais alto revelaram uma preferência por destinações que proporcionassem oportunidades de contato com a natureza ou atividades culturais. Por outro lado, as pessoas com grau de instrução mais baixo ressaltaram a importância das férias em que pudessem tentar atividades novas e pouco familiares, que fossem muito diferentes de suas práticas cotidianas. As pessoas de nível de renda mais baixo viam as suas férias como uma oportunidade de fugir à monotonia do dia-a-dia e de se permitir atividades que lhes dessem autoconfiança. Por outro lado, as pessoas de maiores rendimentos desejavam férias intelectualmente estimulantes e excitantes com a oportunidade de aumentar seus conhecimentos sobre a área visitada.

O desafio está calcado no fato de que não há, na verdade, um fator exato que defina esta questão das motivações e elas não são os únicos determinantes para o consumo de produtos turísticos, mas sim a soma dos recursos do consumidor, conhecimento, atitudes, motivação e personalidade, assim um conjunto de fatores que determinam o comportamento individual enquanto consumidores.

0 poder de decisão do consumidor relaciona-se a fatores de ordem interna (da pessoa) e externa (ambiente) e, consequentemente, podem facilitar ou limitar turistas desejosos de transformar suas motivações e desejos em realidade. A análise de fatores como a disponibilidade, renda, saúde, políticos (terrorismo, natureza do sistema político, restrições a imigração, mídia direcionada as viagens, marketing de agências de viagens, personalidade, estilo de vida e etc.), são de extrema relevância no processo de conhecimento do comportamento do consumidor no turismo.

Considerando o turista pós-moderno é necessário atentar-se para as questões das mudanças tecnológicas, que conferem ao indivíduo mais informações e propicia, portanto, maior poder de escolha e segurança ao organizar e realizar suas próprias viagens. Na modernidade, as motivações de viagens eram muito mais limitadas aos recursos tecnológicos e financeiros, uma vez que o acesso à informação era mais restrito a quem detinha um alto poder aquisitivo, ou aos intermediadores das viagens, as agências. Baseado nos estudos de Molina (2003), Figueiredo e Ruschmann (2004), Panosso Netto e Gaeta (2010), sugere-se alguns fatores relacionados às motivações de viagens nas épocas distintas da evolução do turismo mundial. Conforme o quadro 1.

Quadro 1 Fatores de Motivação de Viagens

\begin{tabular}{|l|l|}
\multicolumn{1}{|c|}{ Turista Moderno } & \multicolumn{1}{c|}{ Turista Pós-moderno } \\
\hline Pouca informação & Muita informação \\
\hline Viagens em grupo & Viagens individuais \\
\hline Pacotes definidos & Pacotes personalizados \\
\hline
\end{tabular}

(continua...) 
Quadro 1 - Continuação

\begin{tabular}{|l|l|}
\multicolumn{1}{|c|}{ Turista Moderno } & \multicolumn{1}{c|}{ Turista Pós-moderno } \\
\hline Viajante passivo & Viajante ativo \\
\hline Evasão, busca de conhecimento & Viver uma experiência \\
\hline
\end{tabular}

Fonte: Elaborado pelos próprios autores.

Ao analisar o perfil do consumidor do turismo ao longo de sua história, identificam-se várias mudanças na forma de relacionar-se com o destino, nas motivações e no comportamento ao se consumir produtos e serviços turísticos. A identificação destas alterações é fundamental para os gestores e empreendedores do turismo, pois a partir dela é possível traçar estratégias de atuação e consolidação no mercado. A sobrevivência da atividade turística enquanto prestadora de serviços depende, então, de sua adaptação às mudanças da sociedade nos aspectos social, político e econômico, além das expectativas do cliente (Panosso Netto e Gaeta, 2010).

Dentre as inúmeras empresas envolvidas no deslocamento e estada do turista/viajante - transportes, hotéis, restaurantes - destacamos as agências de viagens como um canal de distribuição entre fornecedores e consumidor final (turista/viajante), tendo em vista a sua importância na facilitação da viagem e acesso aos produtos turísticos através da identificação das necessidades e anseios dos consumidores.

As agências de turismo são empresas comerciais com a finalidade de realizar viagens. Por conseguinte, são prestadoras de serviços, que informam, organizam e tomam todas as medidas necessárias, em nome de uma ou mais pessoas que desejam viajar. Oferecem todas as prestações de serviços relativas a transportes, hotelaria e manifestações turísticas de todos os tipos, e organizam viagens individuais ou coletivas e um preço determinado, seja através de programas estabelecidos por elas mesmas, seja pela livre escolha dos clientes. (Beni, 1998, p.182).

Embora fosse possível a existência da prestação de serviços a viajantes de forma espontânea desde os tempos antigos, a literatura ocidental registra o seu surgimento em meados do século XIX, com a Thomas Cook and Son inicialmente na Europa, e depois na América do Norte (Tomelin, 2001). Até então as viagens eram realizadas aleatoriamente, em transportes rudimentares, com duração indefinida aliados a escassez de infraestrutura e segurança, ou seja, sem muitas possibilidades de planejamento.

Segundo Andrade (1992), as agências consideradas antigas se dedicavam aos tours individuais de clientela burguesa e a partir de 1930 tornaram-se especializadas em excursões de tours focadas em grupos. Já na década de 1950 o mercado se expande e uma clientela de um poder aquisitivo regular passa a ser atendida e, assim, as agências passam a se dedicar à venda e excursões de pacotes em receptivos de veraneio de padrão médio e a preços acessíveis para cativar as pessoas e construir um fluxo de demanda constante ou regular, fato relacionado a expansão do mercado hoteleiro e dos transportes aéreos.

Ao fim do século XX, as políticas econômicas brasileiras afetaram negativamente a economia das organizações do setor quando as agências de viagens começaram a sofrer com a redução no percentual de comissionamento pela comercialização dos bilhetes aéreos internacionais e nacionais, por conta de decisão de 
diversas companhias aéreas, seguindo uma tendência internacional surgida nos Estados Unidos (Tomelin, 2001).

O impacto do surgimento da internet como nova ferramenta operacional e comercial associado à eventual desregulamentação do transporte aéreo e a demais fatores marcantes no final do século XX são desafios que o setor de viagens vem enfrentando na entrada do novo século e milênio, com efeitos no perfil do agente de viagens, marcado pela desintermediação dos serviços, pela reintermediação dos novos tipos de agência que estão surgindo e, objetivamente, pela alternativa de reposicionamento do seu perfil. (Tomelin, 2001, p.22).

Neste cenário onde as informações e as facilidades de empreendimento das viagens são diversas e acessíveis o redirecionamento estratégico das agências de viagem torna-se essencial. 0 turista procura um intermediador que o conheça $\mathrm{e}$ entenda seus sentimentos e necessidades de maneira intimista, uma "sinergia de fenômenos arcaicos e do desenvolvimento tecnológico" (Maffesoli, 2001).

Diante do exposto, cabe as agências de viagens, dedicação, responsabilidade, dinamismo, sobretudo se adequar as novas tendências do mercado para que assim possa desenvolver uma gestão empresarial voltada para satisfazer as necessidades de seus consumidores. Panosso Netto e Gaeta (2010) destacam que os gestores de turismo não devem apenas elaborar estratégias para atender este novo consumidor só para se consolidarem no mercado, mas porque o consumidor do turismo e o contexto no qual se integra apresentam, atualmente, características que favorecem a experiência e nos leva a pensar na autenticidade dos produtos e serviços.

\section{O TURISTA CONTEMPORÂNEO E A EXPERIÊNCIA: UMA VISÃo DAS AGÊNCIAS DE VIAGENS E TURISMO dE NATAL-RN}

Diante dos posicionamentos supracitados com relação às novas tendências de comportamento do turista e a necessidade de estratégias para atender a este novo perfil, apresenta-se de forma sucinta uma pesquisa realizada junto aos agentes de viagens do município de Natal - RN. As mudanças do ponto de vista do consumidor identificadas foram muitas desde a escolha pelos destinos, passando pela maneira de se realizar as viagens, encerrando com o fator principal motivação.

De acordo com os agentes, os destinos internacionais procurados pelos passageiros acerca de 10 anos atrás eram Estados Unidos (Miami, New York, Orlando), Argentina (Buenos Aires), Europa e nacionais (Rio de Janeiro, Gramado). Estes deslocamentos se davam geralmente em grupo, para adquirir conhecimento e realizar compras. Eram realizadas uma vez por ano e em destinos como a Europa as viagens chegavam a durar 30 dias.

Atualmente os clientes buscam destinos menos massificados como Europa (Leste Europeu), Singapura, Argentina (Vinícolas em Mendonza), ambientes ligados a natureza (Fernando de Noronha, Manaus, Foz do Iguaçu), cruzeiros e resorts. A maioria destes deslocamentos é individual, para vivenciar experiências culturais e gastronômicas. Ainda procuram serviços que representem mais a rea- 
lidade local dos destinos visitados, como o caso de restaurantes típicos, tradicionais e familiares. A solicitação dos produtos e serviços efetuados pelos clientes as agências dependendo da destinação se resumem a hotel, passagem aérea, serviços de transfer e seguro viagem. As viagens estão mais curtas, com duração de 10 a 15 dias dependendo do destino escolhido. Apesar da diminuição do tempo da viagem a frequência aumentou para 02 ou 03 vezes ao ano.

Para os agentes entrevistados, o cliente está mais exigente e chega à agência já com a ideia da viagem, e, neste caso, as agências atuam com a elaboração do forfait (pacote personalizado) para atender tais necessidades. Os grupos de viagem ainda permanecem, mas sugerem uma maior tendência aos pacotes personalizados.

Foi observado também que os clientes que evidenciam a necessidade de uma experiência turística e pessoal são aqueles com poder aquisitivo mais alto, uma vez que representam um público experiente em viagens. 0 consumidor que nunca ou pouco viajou procura a agência para obter informações e ainda solicita excursões para realizar suas viagens e sinalizam que para destinos massificados, a programação da viagem pode até ocorrer de forma autônoma, porém quando tratam-se de destinos poucos divulgados na mídia procuram os pacotes programados das agências de viagens, conferindo maior segurança ao processo de organização da viagem.

Embora de forma muito tímida, os resultados da pesquisa contribuem com a proposição de que o consumidor do turismo tem buscado experiências em suas viagens. Esta afirmação é respaldada na observação de uma maior interiorização nos destinos turísticos, a procura por viagens individuais e a redução do tempo de permanência nos destinos consolidados, podendo aumentar quando o turista busca experiências de contato com a natureza. 0 consumidor não chega na agência dizendo que quer viver uma experiência, no entanto, os destinos propostos e a forma de organizar sua viagem são sinalizadores de tal tendência.

Nota-se que apesar de terem conhecimento deste novo perfil do consumidor e reconhecerem que hoje a viagem não está dissociada da experiência que ela proporciona, poucas ações estratégicas têm sido utilizadas pelas agências.

\section{CONSIDERAÇões finats}

O turismo, como atividade humana e social, sofre mudanças que acompanham as conjunturas históricas, políticas, sociais e econômicas de cada época. Avanços tecnológicos, as novas relações entre tempo e espaço e as concepções humanas sobre seu meio social e ambiental contribuem para significativas evoluções no campo das viagens e do turismo.

Embora as motivações de viagens se apresentem de maneira diversa ao longo dos tempos, alguns estudiosos apontam que o espírito de errância parece ser inerente à natureza humana. A aventura, a curiosidade e o estranhamento representam elementos persistentes na evolução histórica dos viajantes e passam a ser reconsiderados nas motivações de viagens dos turistas no mundo contemporâneo.

O turista pós-moderno aos poucos deixa de ser passivo na organização de suas viagens e cada vez mais reconhece seu poder de decisão e escolha, em con- 
sonância aos seus desejos e necessidades, e espera das viagens um acontecimento memorável, uma experiência de vida, algo que se conecte ao seu passado e ressignifique suas lembranças.

Neste sentido, a subjetividade e a experiência individual tornam-se elementos fundamentais das motivações de viagens, da "mercadoria turismo" escolhida e do retorno, estabelecida por novas relações entre tempo, espaço e sujeito. Portanto, na pós-modernidade o viajante confunde-se em turista e vice-versa e a dinâmica da viagem programada passa a ser complexa uma vez que envolve inúmeros fatores que não somente o anticotidiano, o status social, ou o consumo de bens e serviços turísticos.

Diante dessa complexidade do sujeito turista e de suas motivações, iniciativas, decisões e realizações, é preeminente o dinamismo para as empresas turísticas, principalmente, as agências de viagem. Conhecer seu cliente, ou melhor, a pessoa é fundamental para garantir uma experiência turística autêntica aos sentidos de quem viaja. E mais ainda, conhecer seus fornecedores e parceiros, para que também consigam atender às necessidades deste sujeito e assim contribuírem de forma integrada à experiência de viagem.

Pensar o turismo contemporâneo não é descartar os elementos de natureza econômica e mercadológica que o constitui, mas compreender que sua essência está nas viagens como prática humana e que o turismo, como fenômeno social, é humano e toda a subjetividade que isto implica.

As agências de viagens e turismo que forem capazes de entender o turista não somente como cliente, mas como pessoa que busca nas viagens sua realização de vida, serão àquelas que continuarão a de fato intermediar os serviços turísticos e encontrarão possibilidades de expandir a sua oferta.

Este trabalho não se esgota em si mesmo, intenciona, contudo, instigar a realização de novos estudos, com um maior aprofundamento não só em sua temática como sua abrangência, assim como também na realização deste assunto sob novas perspectivas.

\section{REFERÊNCIAS}

ANDRADE, J.V. (1992). Turismo: fundamentos e dimensões. São Paulo: Ática.

BENI, M. (1998). Análise Estrutural do Turismo. São Paulo:Senac.

BENI, M.(2003) Globalização do Turismo: megatendências do setor e a realidade brasileira. São Paulo: Aleph.

BOYER, M. (2003). História do turismo de massa. Bauru, SP: Edusc.

CISNE, R.; GASTAL, S.(2010, julho). Turismo e sua história: rediscutindo periodizações. Anais do VI Seminário de Pesquisa em Turismo do Mercosul. Caxias do Sul- RS.

COOPER, C. (2007). Turismo: princípios e práticas. Porto Alegre: Bookman.

De LA TORRE PADILLA, O. (1994). El turismo: fenomeno social. Mexico, D.F :Fondo de Cultura Economica.

FIGUEIREDO, S. L. (2010).Viagens e Viajantes. São Paulo: Annablume.

FIGUEIREDO, S.; RUSCHMANN, D. V. R (2004) Estudo genealógico das viagens, dos viajantes e dos turistas. Novos Cadernos NAEA,7 (1), 155-188. 
IRVING, M. de A.; BURSZTYN, I.; SANCHO, A. P.; MELO, G. de M. (2005). Revisitando significados em sustentabilidade no planejamento turístico. Caderno virtual de turismo, 5 (4), 1-7.

KRIPPENDORF, J. (2001). Sociologia do turismo: para uma nova compreensão do lazer e das viagens. São Paulo: Aleph.

MAFFESOLI, M. (2001). Sobre o nomadismo. Rio de Janeiro: Record.

MEYER, J.T. (2007). 0 turismo como fenômeno social de inversão. Trabalho de conclusão de Curso de graduação em Turismo da Pontifícia Universidade Católica do Rio Grande do Sul. 68p.

MOLINA, S. (2003) 0 pós-turismo. São Paulo: Aleph.

MOLINA, S. (2004) Pós-turismo: novas tecnologias e novos comportamentos sociais. In: MOESCH, M.; GASTAL, S. (org.).Um outro turismo é possível. São Paulo: Contexto.

PANOSSO NETO, A. e GAETA, C. (2010). Turismo de Experiência. São Paulo: SENAC São Paulo.

PAnOSSO NETO, A. (2005). Filosofia do Turismo: Teoria e epistemologia. São Paulo: Aleph.

PEZZI, E.; VIANNA, S.L.G. (2015).A Experiência Turística e o Turismo de Experiência: um estudo sobre as dimensões da experiência memorável. Turismo em Análise, 26(01), 165-187.

SHELLER, M.; URRY, J. (2004) Places to play, places in play. In: SHELLER, M.; URRY, J. (ed.). Tourism mobilities: places to play, places in play.London: Routledge.

SWARBROOKE,J.; HORNER, S. (2002). O comportamento do consumidor no turismo. São Paulo: Aleph.

TOMAZZONI, E. L.; DORION, E.; ZOTTIS, A. M. (2008). Análise Organizacional de Destinos Turísticos com Base nos Conceitos de Mudança, de Incerteza e na Teoria do Caos: estudo dos exemplos de Gramado e Canela, na Serra Gaúcha. Organização e Sociedade,15(47), 137-154.

TOMELIN, C. A. (2001). Mercado de Agências de Viagens e Turismo: como competir diante das novas techologias. São Paulo: Aleph.

URIELY, N. (2005). The tourist experience, conceptual developments. Annals of Tourism Research. 32 (1), 199-216.

URRY, J. (2001). O olhar do turista: lazer e viagens nas sociedades contemporâneas. São Paulo: SESC São Paulo.

Recebido em: 04/02/2017

Aprovado em: 28/08/2017

\section{Contribuição}

Ana luiza de Albuquerque Tito: Construção da Pesquisa/artigo; Discussão acerca da CONSTRUÇÃo do ARTigo; BuSCA DE REFERÊnCIAS; PESQUiSA JUnTo ÁS AGÊNCIAS DE VIAGENS.

Paula Normandia Moreira Brumatti: CoNSTRUÇÃO DA IDEIA DA PESQUISA/ARTIGO; PESQUiSA E LEITURA SOBRE REFERÊNCIAS TEÓRICAS PARA CONSTRUÇÃO DO TEXTO; ELABORAÇÃo dO ARTIGO; REVISÃo E COLABORAÇÃo NA ADEQUAÇÃO DO ARTIGO PARA PUBLICAÇÃO.

Wilker Ricardo de Mendonça Nóbrega: COLABORAÇÃO NA CONSTRUÇÃo DA PESQUISA/ ARTIGO; DISCUSSÃO NA CONCEPÇÃO INICIAL DA PESQUISA; INDICAÇõES DE REFERÊNCIAS ADERENTES À PESQUISA; REVISÃo E LAPIDAÇÃO FINAL DA PESQUISA E TEXTO FINAL. 